\title{
KAZAK ETNONIMI*
}

\section{Lawrence Krader}

\section{Çeviren: Serkan Acar**}

Etnonim tetkikleri evvelce incelenmiş birtakım meseleler üzerine inşa edilmelidir: Kavmin kimliği, etnonimin biçim ve muhtevasının tarihi, adlandırılan kavmin öz niteliği, kavmin kendini nasıl adlandırdığı, söz konusu ismin etimolojik ve mantıkî manası gibi. Dolayısıyla Kazakların kavmî kimlik meselesi de etnonimi ile bağlantılı olarak ele alınmalıdır zira zikredilen topluluk XVIII. ve XIX. yüzyıllarda Kırgız adıyla anılmış ve Kazakların bir kısmı da kendilerini bu şekilde tesmiye etmişlerdir. Bahis konusu etnonimin bu niteliği günümüzde Kazak ve Kırgız olarak bilinen halklar arasında yakın ve türü kendine özgü bir münasebetin var olduğu faraziyesini doğurmuş̧tur. Yakın mazide bu iki halkın aynı etnonim altında ittihat etmesinin sağlam bir tarihî mesnedi yoktur.

Kazaklar, Orta Asya tarihinin geç Cengizîler devrinde zuhur eden halef devletler ile hanlıklar zamanının kaotik koşulları altında bir halk olarak teşekkül ettiler. Bu oluşum süreci XV. yüzyılın sonları ile XVI. yüzyılın başlarında vuku buldu. Kazaklar tarih sahnesine çıktıklarında göçebe çobanlar idiler. Otlakları esasen Çağatay Ulusu'nun doğu kısmında yer alıp Çu Irmağı boyunca uzanan bölgede idi. Özbek Ulusu hanlarına bağımlı iken XV. yüzyılın sonunda kopmalar başladı ve akabinde diğer Özbek boyları da onlara katılınca XVI. yüzyılın başlarında Kâsım Han'ın idaresinde birleşik bir federasyon teşekkül etti. Nihayet daha başka Türk göçebeler de Kazak Orda'ya iltihak ettiler. Bu sıralarda Kazak adı, siyasî federatif bir mana yükleninceye kadar, etnik bir anlam kazandı. Bahis konusu dönemde Kazaklar bir halka dönüştü. Etnik bütünlüklerini XV. Yy.dan günümüze kadar fasılaya uğratmaksızın devam ettirdiler.

\footnotetext{
* Lawrence Krader, “Ethnonymy of Kazakh”, The Uralic and Altaic Series, Vol. 13, 1962, pp. 123-128.

** Yrd. Doç. Dr., Ege Üniversitesi, Edebiyat Fakültesi, Genel Türk Tarihi Anabilim Dalı, İzmir. Makalenin dipnotları ve bibliyografyası, kullanılan eserlerin orijinalleri esas alınarak tarafımızdan tamamlanmıştır.
} 
Bilindiği üzere, içtimaî-siyasî örgütlenmeleri üç ordadan müteşekkildi ve bunlar "cüz" tesmiye olunurdu. Bu ordalar da tıpkı boylar, soylar ve sülaleler gibi kıdem esasına dayalı olarak sıralanmıştı. Meratip bakımından en üstünü, Balkaş Gölü ile Issık Göl arasındaki yarı bozkır ve bozkırdan ibaret Yedisu (Semireçye) bölgesinde göçebe hayat süren "Uluğ Cüz" (Büyük Orda) idi. Zikredilen saha hakikaten Kazakların en eski iskân sahasına çok yakındı. "Orta Cüz” (Orta Orda) Merkezî Kazakistan’da, Balkaş Gölü’nün kuzeyinden Güney Sibirya orman-bozkır kuşağına kadar uzanan sahada, mukim göçebelerden ibaretti. "Kiçi Cüz" (Küçük Orda) ise Orta Cüz'ün batısında, Aral Gölü’nün kuzeybatısından Hazar Denizi ve Ural Irmağı'na kadar olan bölgede, bulunuyordu. XVIII. yüzyılın sonlarında Ural Dağları'nın ötesinde, Urallar ile İtil Irmağı arasındaki bozkırlarda yaşayan Kazaklar tarafından kendilerini "Bükey Orda" suretinde adlandıran dördüncü bir cüz daha teşekkül etmişti. Bu bozkırlarda yaşayan Kalmuklar 1770'lerde Çin'e doğru göç edince Kazaklar burayı işgal etmişlerdi. Asya'da hemhudut bölgelere yerleşen Kazaklar XV. yüzyılın sonundan XVIII. yüzyılın başlarına kadar siyasî birliklerini korudular. Birleşik bir devlet olarak nihaî ikbal dönemlerini XVII. yüzyılın sonu ile XVIII. yüzyılın başlarında, Tauke/Teuke Han zamanında yaşadılar.

Kazaklar XIX. yüzyıl literatüründe "Kırgız-Kaysak" ya da sadece "Kırgız" adıyla bilinirdi. Bu devrin önde gelen Kazak entelektüellerinden Velihanov ve Altınsarin kendilerini ve halklarını Kırgız adıyla anmışlardır. Çokan Çingisoviç Velihanov son Orta Cüz hanının soyundan gelmekte idi ${ }^{1}$. Velihanov, etnografik notlarında "Büyük Kırgız-Kaysak Orda" (Большая Киргиз-Кайсацкая орда) ile Kırgız Kazakların kökenini (Происхождение же народа Киргизского Казак) tasvir etmiştir ${ }^{2}$ Ona göre; Kırgızlar (şimdiki terminojide) kendilerine Kırgız, Kazaklar ise (şimdiki terminojide) onlara "Ak Kalpaktı" (Ak Kalpaklar, Белошапочние) уа da sadece "Kara” demekte idiler ${ }^{3}$. Kara adlandırması onların içtimaî ve siyasî örgütlenmelerinde bir asilzâdeden yoksun olduklarına delalet etmektedir. Altınsarin tarafindan mahalli lisanda derlenip neşredilen bir okuma parçası "Kırgız Krestomatisi" (Киргизская Хрестоматия) başlığını taşımaktadır ${ }^{4}$. Bahis konusu Kırgız terimi bir yandan "Kara-Kırgiz" (ayrica modern Kırgız dilinde 'Дикокаменные Киргизы' ve XIX. yüzyılda 'Burut' da denirdi ) manasına gelirken, diğer yandan Kırgız tabirinin bu devirde Kırgız-Kazak ve Kara-Kırgız'ı birlikte kapsayan bir üst anlam kazandığı da ileri sürülmektedir.

\footnotetext{
${ }^{1}$ Ç. Ç. Valihanov, İzbrannıe Proizvedeniya, Alma-Ata, 1958, s.15-16.

${ }^{2}$ A.g.e., s.117.

${ }^{3}$ A.g.e., s. 287.

${ }^{4}$ İ. Altınsarin, Kirgizskaya Hrestomatiya, Tom I, Orenburg, 1879.
} 
Barthold'a göre; bu terminolojik kimlik saptamasının bazı dayanakları vardı. O, Kazaklar ile Kırgızlar arasında bir bağ kurarak bunları Orhon-Yenisey Yazılıtaşları'nda zikredilen Kırgızlara kadar götürür. Kırgız-Kaysak adı XVIII. ve XIX. yüzyıllarda Rıçkov, Levşin ve daha başkaları tarafından Kazaklara matuf biçimde kullanılmıştır. Schuyler'e göre; Rusçadaki Kırgız-Kaysak kullanım şekli de Kazak adını "Cossack” (Kozak, Kazak) suretinden ayırt etmek içindi; hâlbuki söz konusu ismin kökeni de aynıyd1. ${ }^{5}$ Barthold'un tasdik ettiği bu takrir Pelliot tarafından şüpheyle karşılanmıştır ${ }^{6}$. Orta Cüz’ün Kongrad boyuna bağlı oymaklar 1630 yılından sonra Uluğ Cüz boyları ile beraber ayrı bir birlik oluşturdular ve XIX. yüzyılın başlarına gelindiğinde hâlâ beraber idiler. Onlar da bu sırada kendilerini Kazak olarak adlandırmışlardı ${ }^{7}$.

Barthold'a göre; Cengiz Han İmparatorluğu'nun çöküş sürecinde ayrılan boy ve oymaklar Kazak olarak adlandırıldılar ve yağmacı topluluklara dönüştüler. Minorskiy tarafindan da paylaşılan bu nazariyeye göre; Kazak adı, fiil kökü "kaz-" olup başıboş ve avare anlamına gelen bir cins isimden türemişti ${ }^{8}$. Yüklenen bu anlam Vambéry ve Pavet de Courteille'in eserlerinde mevcuttur. Gombocz'un kök ve anlamını XX. yüzyıl Kumuk lisanına bağladığ 1 bu hüküm Németh tarafından ikmal etmiştir. Dolayısıyla "kaz-" fiil kökünün "başıboş dolaşmak" manası haricîdir. Söz konusu terimin mahalli izahı ise beyaz kaz efsanesinden türeyen bir Kazak halk etimolojisine isnat etmektedir ve buna göre; "Kazak" adı "kaz" ve "ak" kelimelerinin terkibinden oluşmuştur. Son zamanlarda neşredilen bir Kazakistan Tarihi'nde bu halk etimolojisinin kökeni söz konusu beyaz kazın genç bir kıza dönüştüğü ve Kazakların da esasen bundan neşet ettiği bir efsaneye bağlanmıştır. Ayrıca bahis konusu etnonimin "Kaspi" ve "Hazar" kelimelerine müsteniden zuhur ettiğine ilişkin fantastik etimolojiler de mevcuttur'.

Pelliot ise başka bir teklif sunmaktadır. Moğolların Gizli Tarihi'nde (XIII. yüzyıl), Sanang Setsen Kroniği'nde ve Altan Tobçi'de (her ikisinde XVII. yüzyılda yaşamış Moğollar idiler) "Qazaq-tergen" adı "büyük araba" manasına gelmektedir. Ramstedt, söz konusu adın XX. yüzyıl Kalmuk lisanında aynı anlama geldiğini kaydetmiştir. Pelliot, "Qazaq" adının etnonim olarak XIII.

\footnotetext{
${ }^{5}$ P. İ. Rıçkov, Topografiya Orenburgskoy Gubernii, Orenburg, 1762; A. Levşin, Opisanie KirgizKazaçih ili Kirgiz-Kaysatskih Ord i Stepey, St. Petersburg, 1832; E. Schuyler, Turkestan, Vol. 1, New York, 1876, s.30.

${ }^{6}$ V. V. Barthold, “Kazak”, $E I^{1}$, Vol. 2, s. 836; V. V. Barthold, “Khazar”, $E I^{1}$, Vol. 2, s.927-934; Paul Pelliot, Notes sur la Horde d'Or, Paris, 1949, s.219.

${ }^{7}$ Ç. Ç. Valihanov, Soçineniya, St. Petersburg, 1904, s.29, 286.

${ }^{8}$ V. V. Barthold, 12 Vorlesungen über die Geschichte der Türkvölker Mittelasiens, Berlin, 1935, s.195, 215, 235; V. Minorsky, "Transcaucasica”, Journal Asiatique, 2, s.76-92; V. V. Barthold, "Khazar", ayn1 yer.

${ }^{9}$ Ístoriya Kazahskoy SSR, I, Alma-Ata, 1955, s.143, 144.
} 


\section{Lawrence Krader}

yüzyılın başlarına kadar geri gidebileceği hükmüne varmıştır ${ }^{10}$. Bu yorumun çıkmazı bilinen bir etnik zümreyi işaret etmemesi ve sadece kronoloji ile mekân bildirilmesidir. Kaldı ki, bahis konusu isim ile ona yüklenen anlam sadece erken dönem Moğol membalarında görülmekte Türk kaynaklarında ise zikredilmemektedir. İbragimov, Rubehan'1 (XVI. yüzy1l) delil olarak gösterip bu büyük arabaların Kazaklar tarafından kullanıldığını ileri sürmektedir ${ }^{11}$. Mamafih işaret edilen "Xasag-tergen" (Qazaq) halkı Cengizîler öncesi dönemde hâlâ muğlaktır. XV. ve XVI. yüzyıllardan önce, Kazak etnik kimliğini ispat edecek deliller mevcut değildir. Bilinen bir topluluk ile bağlantılı olarak Kazak adının erken tarihini aydınlatabilmek için daha başka kaynakları da tetkik etmek zarurîdir. Sosyal bir tabakanın adı olarak Kazak teriminin erken tarihine ilişkin mühim bir ipucu Velihanov ve Velyaminov-Zernov tarafindan sunulmuştur lakin bunun pek çok araştırmacının gözünden kaçtı̆̆ 1 anlaşılmaktadır. Velyaminov-Zernov tarafindan telif edilen Kâsım Tatarları tarihinde XV. yüzyılın ortalarında kaleme alınan Rus yıllıklarından Kazaklarla ilgili iktibas yapılmıştır: ${ }^{12}$ Даниярь “земли Мещчерьские” участвоваль в походе со всеми своими царевичами, князьями и казаками. (34. Т. е. простым Татарами. Простые Татары, приходившие служить въ Россию вместе съ своими чаревичами, а равным образомъ и простые Татары Казанские Крымские и пр. обыкновенно звались у Русскихъ казаками; да и сами они называли себя казаками) ${ }^{*}$.

“Sofiyskaya Pervaya Letopis”te 6979 (1471) y1lı hadiseleri anlatılirken, Meşçerskiy topraklarında [Kâsım Hanlı̆̆ı] hüküm süren Aydar Kasımoviç nam1 diğer Danyar'dan bahsedilmiştir: ${ }^{13}$ Царева сына Каисымова Аидаара своеи земле Мещчерьские и сь его царевичи, и с князьми и с казаки, и со въсеми их людьми. А от вотчины их Пьсковские земли на них рати приидоша их рубежов своеи земли ${ }^{* *}$.

${ }^{10}$ Pelliot, Notes..., s.215-220.

${ }^{11}$ S. K. İbragimov, "Eşçe Raz o Termine Kazah", Trudı İnstituta İstorii, Arheologii i Etnografii Akademii Nauk Kazahskoy SSR, 1960, 8, s.70-71.

${ }^{12}$ Valihanov, Soçineniya, s. 289; V. V. Velayaminov-Zernov, İzsledovanie o Kasimovskih Tsaryah i Tsareviçah, Tom 1, St. Petersburg, 1863, s.74.

* Müellif İngilizce telif ettiği makalede, Rus kaynağından yaptığı bu iktibası çevirmemiş ve sadece İngiliz usulüne göre transkribe etmiştir. Biz zikredilen metnin orijinal halini verip tercümesini de sunuyoruz: "Danyar 'Meşçerskiy topraklarında' kendi hanzâdeleri, begleri ve kazakları ile birlikte topyekûn sefere iştirak etti. (Dipnot 34. Yani sadece Tatarlar. Hanzâde ile birlikte Rusya'ya hizmet için gelen Tatarlar; keza Kazan Tatarları, Kırım Tatarları vb. de umumiyetle Rus Kazaklar ile birlikte anılırlardı ve onlar da kendilerini Kazak tesmiye ederlerdi)".

${ }^{13}$ Polnoe Sobranie Russkih Letopisey, Tom 6, St. Petersburg, 1853, s.9.

** Rus yıllığından alınan bu bölüm de tercüme edilmemiştir. Orijinal metnin tercümesi şöyledir: “Kâsım Han'ın oğlu Aydar [Danyar] kendi toprağı Meşçerskiy'de hânzadeleri ve begleri ve kazakları ve bütün adamlarıyla birlikte; onların Pskov topraklarındaki yurtluklarına, hudut boylarına muharebeye gitti”. 
$\mathrm{Bu}$ Kazaklar arasındaki ayırt edici özellik, doğrudan doğruya Kâsım Hanedanı'na bağlı olmaları ve daha farklı düşük bir sosyal tabakayı temsil etmeleridir. Velyaminov-Zernov gibi Velihanov da aynı görüşü benimsemiştir. Her ikisi de askerî bir çağrışımı ima etmektedirler.

Gerek Ruslar gerekse Türkler XV. yüzyılın ortalarında Kazak terimi ile bir hânzadenin idaresi altında bulunup, Rusların hizmetine giren ve doğrudan kendi atamanlarına bağlı olan Tatarları imlemişlerdir. Mamafih bunlar muayyen bir boy ya da ulusa bağlı kimseler olarak telakki edilmemiştir. Kazaklar bir ulusun sosyal bir tabakasını ya da bir sınıfını teşkil edebilecekleri gibi Kazan Tatarı, Kırım Tatarı veya daha başka bir Türk topluluğuna da mensup olabilirlerdi. Söz konusu terim günümüzdeki Kazaklar ile yakın bağları olan zümreler; yani tarihî ve linguistik olarak Kuzeybatı Türkleri, Kıpçaklar ya da Nogay Türkleri isimleriyle tanımlanan topluluklar tarafindan da kullanılmıştır. Moğollar ortaçağda ilk kez Kuzeydoğu Türkleri ve Güneydoğu Türkleri ile temasa geçtiklerinde de yine bu adı kullandılar. Bununla birlikte, bu kelime ile sadece Kuzeybatı Türklerine atıf yapıldığı malumumuzdur. Bunlar arasında, geç ortaçağdaki Türk Kazaklar etnik bir zümre değil sosyal bir tabaka olarak tanımlandılar.

"Kazakistan Halkaları Tarihi”ne göre; Kazak devleti veya hanlığı anlamında kullanılan Kazak teriminin siyasî ehemmiyeti zaman içerisinde etnik manasının önüne geçmiştir. Lakin şunu da ilave etmek gerekir ki, söz konusu terimin sosyal bir tabakayı imlemesi belki de hem siyasî hem de etnik kullanımından daha mukaddem idi. Kazak kelimesi XV. yüzyılın ortalarında İtil Türkleri arasında "Kimseye tâbi olmayan savaşçı" manasında kullanılıyor; XV. yüzyılın ahirinde ise Semireçye'de siyasî bir teşekkül anlamına geliyordu. Bahis konusu kullanımlar arasındaki münasebet araştırılmaya devam etmektedir.

Kazak teriminin etnonimik kullanımının haricinde leksikal tarihi ile ilgili olarak Barthold, Rusların bu kelimeyi XV. yüzyılın ikinci yarısında Türklerden aldıklarını kabul edip söz konusu kelimenin etimolojik bakımdan muğlak olduğunu belirtmektedir. Zikredilen dönemde birbirine hemhudut iki linguistik sahadaki kullanım farkı oldukça küçük idi. Kazak terimi sadece askerî anlam ifade eden bir sözcük değil aynı zamanda akraba ya da sahibinden bağımsız manasına da geliyordu; hatta başıboş dolaşıp yağmacılık yapmasalar dahi bu isimle anılıyorlard. Müteakip dönemlerde sadece askerî ehemmiyeti ön plana çıktı $^{14}$. Kazak teriminin bu sonuncu manasının yayılımı A. von Gabain tarafindan tetkik edilmiştir ${ }^{15}$.

\footnotetext{
${ }^{14}$ Barthol, "Kazak”, s.836.

${ }^{15}$ A. von Gabain, “Kasakentum”, AOH, 11, 1960, s.161-167.
} 


\section{Lawrence Krader}

Samoyloviç’in vardığ 1 netice ise şöyledir: "Kazakistan yerli halkının ulusal adı, sosyal bir terimin bir boy adına teşmil olunmuş ikinci bir kullanım şeklini ifade etmektedir. Bu durumda, Kırım Tatar lisanı ve daha başka Türk lehçelerindeki Kazak (Rus) adının hilafına, söz konusu isim yöredeki dillerde bir ulus adı değil de bir ulusun öz adlandırması olarak tebarüz etmiştir” ve hâlâ geçerliliğini korumaktadır ${ }^{16}$. Unutmamak gerekir ki, Kazakların öz adlandırma süreci, bozkırdaki siyasî uygulamaların engellemelerine maruz kalmış ve Kazaklar önce sosyal bir tabaka, akabinde siyasî bir teşekkül ve nihayet siyasî açıdan bütünleşik bir halk olarak zuhur etmiştir.

\section{KAYNAKLAR}

Altınsarin, İ., Kirgizskaya Hrestomatiya, Tom I, Orenburg, 1879.

Barthold, V. V., "Kazak", $E I^{1}$, Vol. 2, s.836.

Barthold, V. V., "Khazar”, EI ${ }^{1}$, Vol. 2, s.927-934.

Barthold, V. V., 12 Vorlesungen über die Geschichte der Türkvölker Mittelasiens, Berlin, 1935.

Gabain, A. von., “Kasakentum”, $A O H, 11,1960$, s. 161-167.

İbragimov, S. K., "Eşçe Raz o Termine Kazah", Trudı İnstituta İstorii, Arheologii $i$ Etnografii Akademii Nauk Kazahskoy SSR, 1960, 8, s.70-71.

İstoriya Kazahskoy SSR, I, Alma-Ata, 1955.

Levşin, A., Opisanie Kirgiz-Kazaçih ili Kirgiz-Kaysatskih Ord i Stepey, St. Petersburg, 1832.

Minorsky, V., "Transcaucasica”, Journal Asiatique, 2, s.76-92.

Pelliot, Paul, Notes sur la Horde d'Or, Paris, 1949.

Polnoe Sobranie Russkih Letopisey, Tom 6, St. Petersburg, 1853.

Rıçkov, P. İ., Topografiya Orenburgskoy Gubernii, Orenburg, 1762.

Samoyloviç, A., "O Slove Kazak”, Kazaki Antropologiçeskie Oçerki, Edt. S. İ. Rudenko, Leningrad, 1927, s.16.

Schuyler, E., Turkestan, Vol. 1, New York, 1876.

Valihanov, Ç. Ç., İzbrannıe Proizvedeniya, Alma-Ata, 1958.

Valihanov, Ç. Ç., Soçineniya, St. Petersburg, 1904.

Velayaminov-Zernov, V. V., İssledovanie o Kasimovskih Tsaryah i Tsareviçah, Tom 1, St. Petersburg, 1863.

\footnotetext{
${ }^{16}$ A. Samoyloviç, “O Slove Kazak”, Kazaki Antropologiçeskie Oçerki, Edt. S. İ. Rudenko, Leningrad, 1927, s.16.
} 